\title{
County Poverty: The Case Of Sacramento
}

Robert G. Mogull (E-mail: mogullr@csus.edu), California State University, Sacramento

\begin{abstract}
This study serves two purposes. First, it demonstrates a method of estimating and projecting annual poverty at sub-national levels. Data are obtained from decennial censuses to form the benchmarks from which poverty is estimated and projected for various demographic groups. Projections are based upon historical curvilinear trends for each group. The methodology can be easily applied in a variety of jurisdictional settings and levels.

The second objective is to provide a specific portrait of poverty by demographic group within the County of Sacramento in the State of California. The evidence indicates that, by the end of the decade, the County poverty rate will rise to $16 \%$ and the number of poor persons will expand to 216 thousand. There will be large differences among the various demographic groups in their rates of change.
\end{abstract}

\section{Introduction}

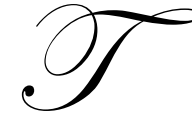

different.

he Bureau of the Census provides two principal estimates of poverty. Both have been conducted since 1960 (for poverty since 1959) and both are widely used in academia, in commerce, by advocacy groups and in government circles at all jurisdictional levels. The two estimates are, however, very

One source of official poverty statistics is the nationwide Current Population Surveys (CPS). These are conducted annually during the month of March and consist of supplemental questions to their basic monthly surveys of employment and unemployment (for the Bureau of Labor Statistics). The supplemental March questions survey income and poverty levels.

The CPS reaches roughly 50,000 civilian non-institutional households nationwide. Beginning in March 2002 (for 2001 income), however, the sample size was approximately doubled. In year 2000, for example, about 51,000 households were sampled throughout the United States, including 275 households within Sacramento County. However, there were over 105 million occupied households in the nation with almost 454 thousand in Sacramento. (The Census Bureau defines a household as consisting of a single individual or group of people who occupy a common housing unit, whether related or not.)

Excluded from the CPS are persons living in college dorms and military base housing (barracks), as well as patients and inmates of institutions. Undocumented aliens and many of the homeless are also not counted. Further, the CPS excludes residents of Puerto Rico and other outlying areas of the U.S. - such as Guam, the Virgin Islands, American Samoa and the Northern Mariana Islands.

Annual CPS poverty data are reported separately for the nation, regions, a few large counties and an aggregation of the 10 largest metropolitan areas. Due to the small samples, state level poverty are reported only as 2-year and 3-year moving averages. The data are categorized by race and by Hispanic ethnicity, where Hispanics are also double-counted by race. These categories currently consist of: Asians, Blacks, Hispanics (of any race), Native Americans, Native Hawaiians \& Other Pacific Islanders, Non-Hispanic Whites, Some Other Race, Two or More Races and Whites. Racial/Hispanic poverty data are not at all reported for sub-national levels. However, even at the national level, the annual racial/Hispanic and age statistics on poverty are highly erratic, unstable, volatile and unreliable. 
The other primary source of official poverty statistics is the decennial censuses, which have been conducted by the Bureau also since 1960. Census data are obtained from all jurisdictional levels throughout the nation and U.S. Territories - including states, counties, cities, towns, tracts and blocks. Data are collected and classified for many separate (but non-mutually exclusive) demographic groups. Census statistics are compiled from much larger samples than the CPS, consisting over the years of between $15 \%$ and $25 \%$ of all civilian non-institutional housing units. In Census 2000, for example, there were almost 17.6 million households in the national sample, including 75,600 in the sample for Sacramento County. Table 1 presents statistics for year 2000 on populations, households and sample sizes in both the CPS and the decennial census for the nation, the State of California and the County of Sacramento.

Table 1: Year 2000 Samples

\begin{tabular}{lrrrr}
\hline Location & $\begin{array}{c}\text { Resident } \\
\text { Population }\end{array}$ & $\begin{array}{c}\text { Occupied } \\
\text { Households }\end{array}$ & $\begin{array}{c}\text { Occupied House- } \\
\text { holds in Decennial } \\
\text { Census Sample* }\end{array}$ & $\begin{array}{c}\text { Occupied House- } \\
\text { holds in CPS Sample }\end{array}$ \\
\hline United States & $281,421,906$ & $105,480,101$ & $17,580,017$ & 51,016 \\
State of California & $33,871,648$ & $11,502,870$ & $1,917,145$ & 4,453 \\
County of Sacramento & $1,223,499$ & 453,602 & 75,600 & 275 \\
\hline
\end{tabular}

Source: Bureau of the Census, U.S. Department of Commerce.

*Based upon $1 / 6^{\text {th }}$ formula.

A third source of official poverty statistics that is now available from the Census Bureau is the Small Area Income and Poverty Estimates (SAIPE). This series was recently introduced in order to provide updated annual estimates of income and poverty, which are necessary for allocating federal funds to local jurisdictions. These intercensus estimates of poverty are provided for small geographic areas - states, counties and school districts. However; the years of statistics that are currently available are very limited, there is an approximate two to three-year lag in producing the statistics, and poverty estimates are not provided for racial/ethnic groups or for other demographic subgroups (such as the elderly and female family heads). Since these "model-based" regression estimates of poverty employ CPS data, the Bureau acknowledges that the sample of households is large enough to provide reliable statistics for only 10 states and a few very large counties.

Thus, annual demographic poverty is not estimated by any official source for sub-national jurisdictions. Although the CPS does provide annual poverty estimates for states, it is reported only for all demographic groups combined. In contrast, decennial census poverty data are available for separate demographic groups and for all jurisdictional levels, but are collected at 10-year intervals only. The purpose of this paper, therefore, is both to fill in for the annual gaps in demographic poverty and to make projections for the next decade. The County of Sacramento is chosen as the demonstration locale.

The official definition of poverty was originally designed in 1963-64 by Mollie Orshansky of the Social Security Administration. The poverty definition and thresholds have provided a consistent measure since 1959 and, in 1969, were formally established for use by all federal agencies. Although annual changes in living costs are factored into the national thresholds (using the CPI-U), there are no regional adjustments. Therefore, since the cost of living in Sacramento is roughly 9\% higher than the national average, County poverty is underestimated. Figure 1 illustrates the changing official thresholds for a family of four, for example, over the decennial census years. The thresholds have grown from $\$ 2,973$ in 1959 to $\$ 17,029$ in 1999 .

\section{Methodology}

In this paper, estimates and projections of annual poverty will be based upon the decennial census tabulations for two reasons. First; because of their far larger sample sizes, decennial census estimates of poverty are more reliable and probably also more accurate. Second; the Current Population Surveys do not report annual poverty for $\mathrm{racial} /$ Hispanic groups at sub-national levels. Thus, yearly race/Hispanic poverty statistics are not available from the CPS at the county level. 


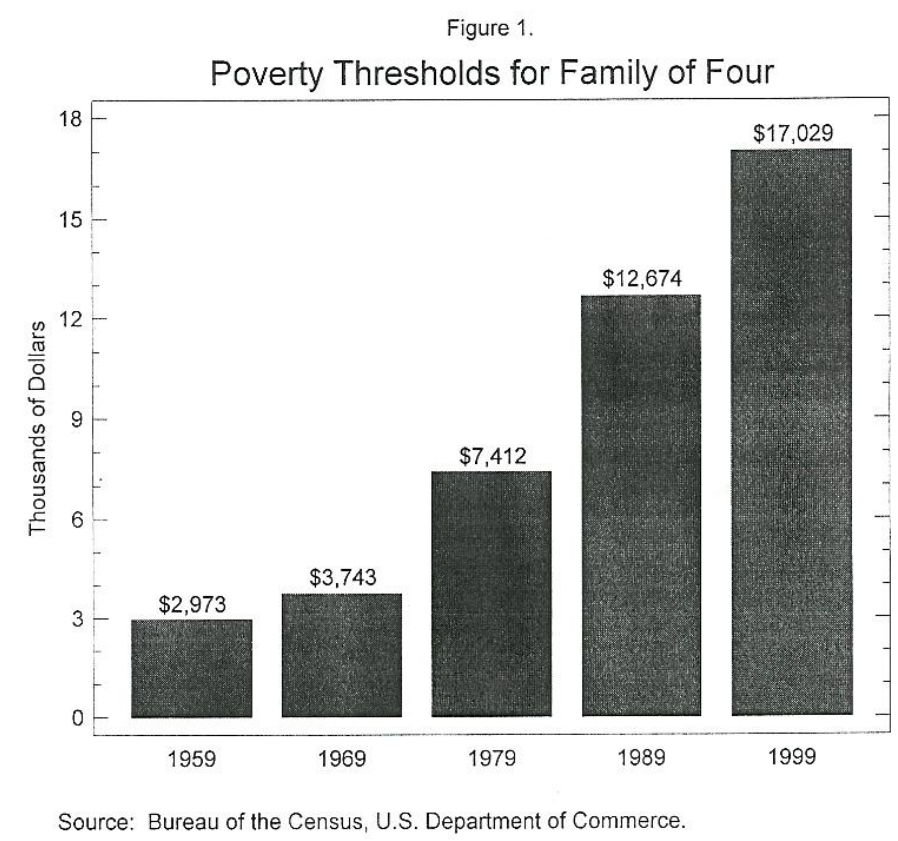

Decennial census data provide discrete benchmarks that will be used to compute continuous smoothed trends in poverty for separate (but non-mutually exclusive) demographic groups within Sacramento County. The universe of benchmark years consists of 1959, 1969, 1979, 1989 and 1999. (These are the years that income was received, not the years when decennial census data were obtained.) Tables 2 and 3 list the officially tabulated poverty rates and numbers of persons, respectively, for various demographic groups within the County over the years. These will be the anchors for the independently computed trend lines.

After the basic trend lines are identified, annual estimates will be interpolated and projections extrapolated, with projections extended for the decade 2000 through 2009. Evidence from the trend lines will clarify the relative incidences and numerical counts of poverty among the demographic groups. The trend evidence will also reveal the directions and comparative speeds of the changing independent patterns of secular poverty.

The trend lines will contain an assortment of assumptions. For example, they assume that intervening years of poverty are accurately portrayed by smoothed temporal estimates. The projections further assume that the historical trends will continue -- such as in rates of fertility, mortality and immigration. In addition; it is presumed that there will not be any major disruptions in the trends due to wars, epidemics, natural disasters (such as an earthquake or flood) or special events (such as a major expansion of the gaming industry and its particular impact on the incomes of Native Americans). The variable "Year" serves as a collective proxy for a wide variety of economic, social, psychological and chance factors that can affect poverty over time. 
Table 2: Decennial Census Poverty Rates Sacramento County, California

\begin{tabular}{|l|c|c|c|c|c|}
\hline Group & $\mathbf{1 9 5 9}$ & $\mathbf{1 9 6 9}$ & $\mathbf{1 9 7 9}$ & $\mathbf{1 9 8 9}$ & $\mathbf{1 9 9 9}$ \\
\hline All Persons & 11.0 & 10.6 & 11.2 & 12.5 & 14.1 \\
Asians \& Pacific Islanders & $\mathrm{n} / \mathrm{a}$ & $\mathrm{n} / \mathrm{a}$ & 12.4 & 23.4 & 20.6 \\
Asians & $\mathrm{n} / \mathrm{a}$ & $\mathrm{n} / \mathrm{a}$ & $\mathrm{n} / \mathrm{a}$ & 23.7 & 20.5 \\
Native Hawaiians \& Other Pacific Islanders & $\mathrm{n} / \mathrm{a}$ & $\mathrm{n} / \mathrm{a}$ & $\mathrm{n} / \mathrm{a}$ & 18.2 & 22.2 \\
Blacks & $\mathrm{n} / \mathrm{a}$ & 26.7 & 24.0 & 24.0 & 23.7 \\
Children (related, under age 18) & $\mathrm{n} / \mathrm{a}$ & $\mathrm{n} / \mathrm{a}$ & 15.4 & 19.5 & 20.2 \\
Elderly (age 65 and over) & $\mathrm{n} / \mathrm{a}$ & 17.3 & 8.0 & 6.8 & 6.6 \\
Female Family Heads & $\mathrm{n} / \mathrm{a}$ & 30.5 & 28.1 & 28.3 & 23.4 \\
Hispanics (of any race) & $\mathrm{n} / \mathrm{a}$ & 16.4 & 18.3 & 19.5 & 19.5 \\
Native Americans & $\mathrm{n} / \mathrm{a}$ & $\mathrm{n} / \mathrm{a}$ & 23.6 & 19.7 & 20.9 \\
Some Other Race & $\mathrm{n} / \mathrm{a}$ & $\mathrm{n} / \mathrm{a}$ & $\mathrm{n} / \mathrm{a}$ & $\mathrm{n} / \mathrm{a}$ & 22.0 \\
Two or More Races & $\mathrm{n} / \mathrm{a}$ & $\mathrm{n} / \mathrm{a}$ & $\mathrm{n} / \mathrm{a}$ & $\mathrm{n} / \mathrm{a}$ & 17.7 \\
Whites & $\mathrm{n} / \mathrm{a}$ & $\mathrm{n} / \mathrm{a}$ & 9.2 & 9.0 & 10.1 \\
Non-Hispanic Whites & $\mathrm{n} / \mathrm{a}$ & $\mathrm{n} / \mathrm{a}$ & $\mathrm{n} / \mathrm{a}$ & 8.6 & 9.5 \\
\hline
\end{tabular}

Source: Bureau of the Census, U.S. Department of Commerce.

Table 3: Decennial Census Poverty Persons Sacramento County, California

\begin{tabular}{|l|c|c|c|c|c|}
\hline Group & $\mathbf{1 9 5 9}$ & $\mathbf{1 9 6 9}$ & $\mathbf{1 9 7 9}$ & $\mathbf{1 9 8 9}$ & $\mathbf{1 9 9 9}$ \\
\hline All Persons & 53,871 & 66,315 & 86,470 & 126,783 & 169,784 \\
Asians \& Pacific Islanders & n/a & n/a & 5,035 & 22,389 & 28,878 \\
Asians & n/a & n/a & n/a & 21,518 & 27,499 \\
Native Hawaiians \& Other Pacific Islanders & n/a & n/a & n/a & 1,110 & 1,379 \\
Blacks & n/a & 9,415 & 13,699 & 21,884 & 27,184 \\
Children (related, under age 18) & n/a & 28,139 & 31,432 & 51,972 & 65,901 \\
Elderly (age 65 and over) & n/a & 7,759 & 5,654 & 7,130 & 8,628 \\
Female Family Heads & n/a & 5,660 & 9,319 & 14,415 & 14,580 \\
Hispanics (of any race) & n/a & 9,384 & 13,248 & 22,247 & 37,441 \\
Native Americans & n/a & n/a & 2,303 & 2,447 & 2,749 \\
Some Other Race & n/a & n/a & n/a & n/a & 19,540 \\
Two or More Races & n/a & n/a & n/a & n/a & 13,384 \\
Whites & n/a & n/a & 57,445 & 68,810 & 78,049 \\
Non-Hispanic Whites & n/a & n/a & n/a & 60,212 & 66,024 \\
\hline
\end{tabular}

Source: Bureau of the Census, U.S. Department of Commerce.

\section{The Evidence}

\subsection{The Past}

Figures 2 and 3 below are graphic illustrations of the universe of census benchmark poverty statistics for Sacramento County, which are contained in Tables 2 and 3. Figure 2 shows the incidence of poverty within each group over the five decennial censuses for which poverty statistics were compiled. The data points are connected by lines in order to facilitate a visual comparison of levels and trends among the various groups. (The lines are not created by regressions.)

It is apparent from Table 2/Figure 2 that:

- $\quad$ The overall rate of poverty for all County residents declined during the 1960 s and then rose at accelerated rates over the next three decades. Between 1959 and 1999, the incidence rose more than 28\%, from $11 \%$ to a peak of $14.1 \%$. 
- $\quad$ Poverty rates among Asians \& Pacific Islanders exploded by $89 \%$ in the 1980 s and peaked at $23.4 \%$ in 1989, before dropping to $20.6 \%$ in 1999 . Between 1979 and 1999 , rates rose by $66 \%$. Among Asians alone, the incidence of poverty fell $14 \%$ during the 1990 s, from $23.7 \%$ to $20.5 \%$. However, among Native Hawaiians \& Other Pacific Islanders alone, rates rose $22 \%$ from $18.2 \%$ to $22.2 \%$.

- Black poverty rates receded by $11 \%$, from $26.7 \%$ in 1969 to $23.7 \%$ in 1999 . Yet, their rates remain above those of all other racial/Hispanic groups.

- $\quad$ The incidence of poverty among Children (related, under age 18 ) increased $31 \%$ over the past two decades, from $15.4 \%$ in 1979 to $20.2 \%$ in 1999 . A greater rise occurred in the 1980 s at $27 \%$, compared to $4 \%$ during the 1990s.

- $\quad$ Elderly poverty rates plummeted 62\% between 1969 and 1999, from $17.3 \%$ to 6.6\%. Decade-by-decade declines have been continuous but diminishing. During the 1970 s there was a $54 \%$ shrinkage, during the 1980s the shrinkage was $15 \%$ and during the 1990 s the contraction was $3 \%$. For the past 20 years, Elderly rates have been the lowest of all measured demographic groups.

- $\quad$ The incidence among Female Family Heads declined 23\%, from 30.5\% in 1969 to $23.4 \%$ in 1999. Nevertheless, their poverty rates typically exceed those of all other demographic groups.

- Hispanic rates rose by $19 \%$, from $16.4 \%$ in 1969 to $19.5 \%$ in 1999 . There was no change in their rate between 1989 and 1999.

- $\quad$ Among Native Americans, the poverty rate fell by $11 \%$ between 1979 and 1999 -- declining $17 \%$ during the $1980 \mathrm{~s}$ and then rising $6 \%$ in the $1990 \mathrm{~s}$.

- $\quad$ The poverty rate for Some Other Race was a comparatively high $22.0 \%$ in 1999.

- $\quad$ Among Two or More Races, the poverty rate in 1999 was $17.7 \%$.

- White poverty rates declined slightly in the 1980s and then rose $12 \%$ during the 1990 s. Between 1979 and 1999, there was a $10 \%$ net increase. With the exception of Non-Hispanic Whites, rates among Whites in general were the lowest of all racial/Hispanic groups. The rate of poverty among Non-Hispanic Whites rose by $11 \%$, from $8.6 \%$ in 1989 to $9.5 \%$ in 1999 . Their rates lie below those of all other racial/Hispanic groups.

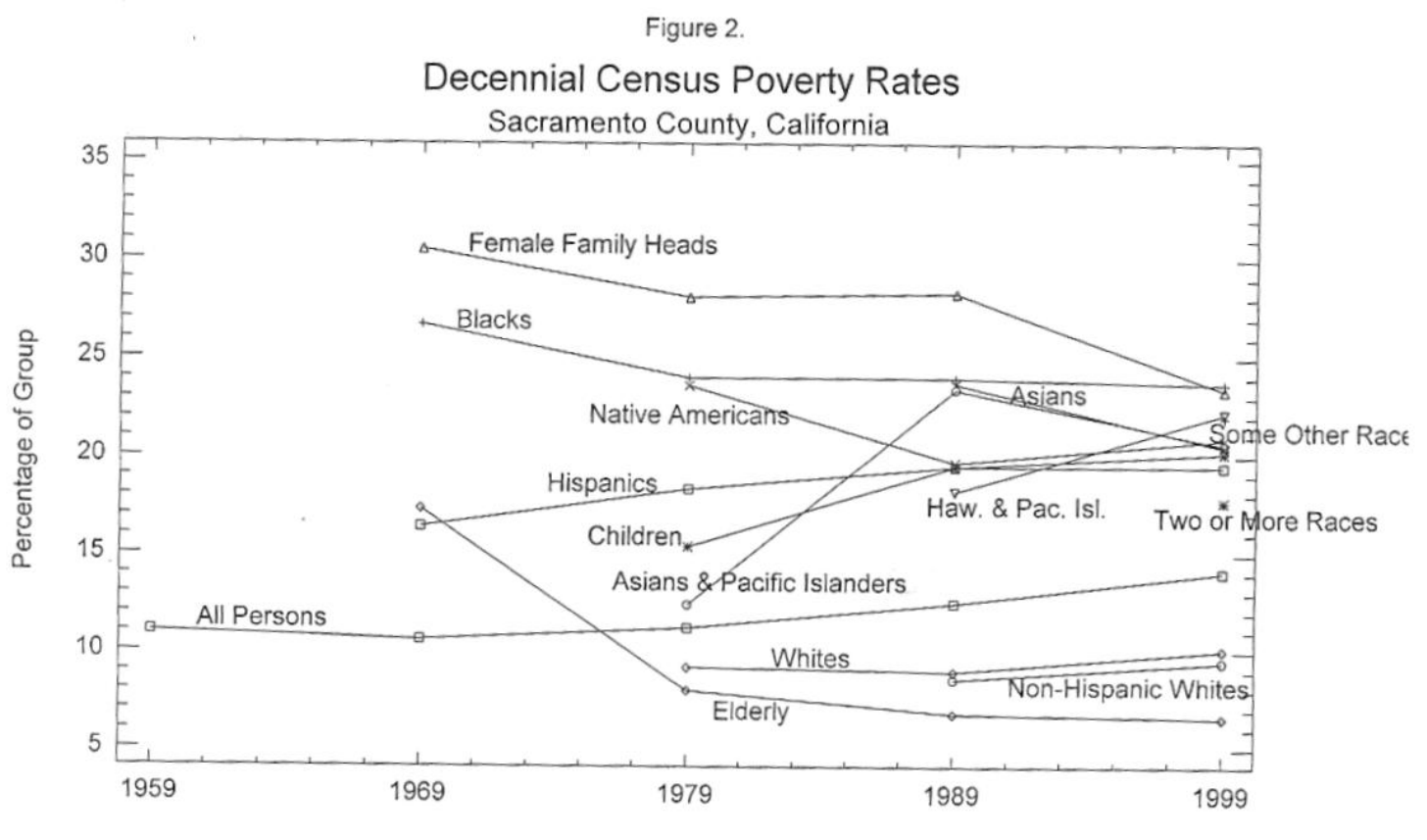

Source: Bureau of the Census, U.S. Department of Commerce. 
Figure 3 indicates the number of impoverished residents by demographic group. These numbers can fluctuate over time due to changes in internal poverty rates and/or to changes in the number of residents affiliated with that group. Table 3/Figure 3 contribute to a more complete picture of historical poverty within the County.

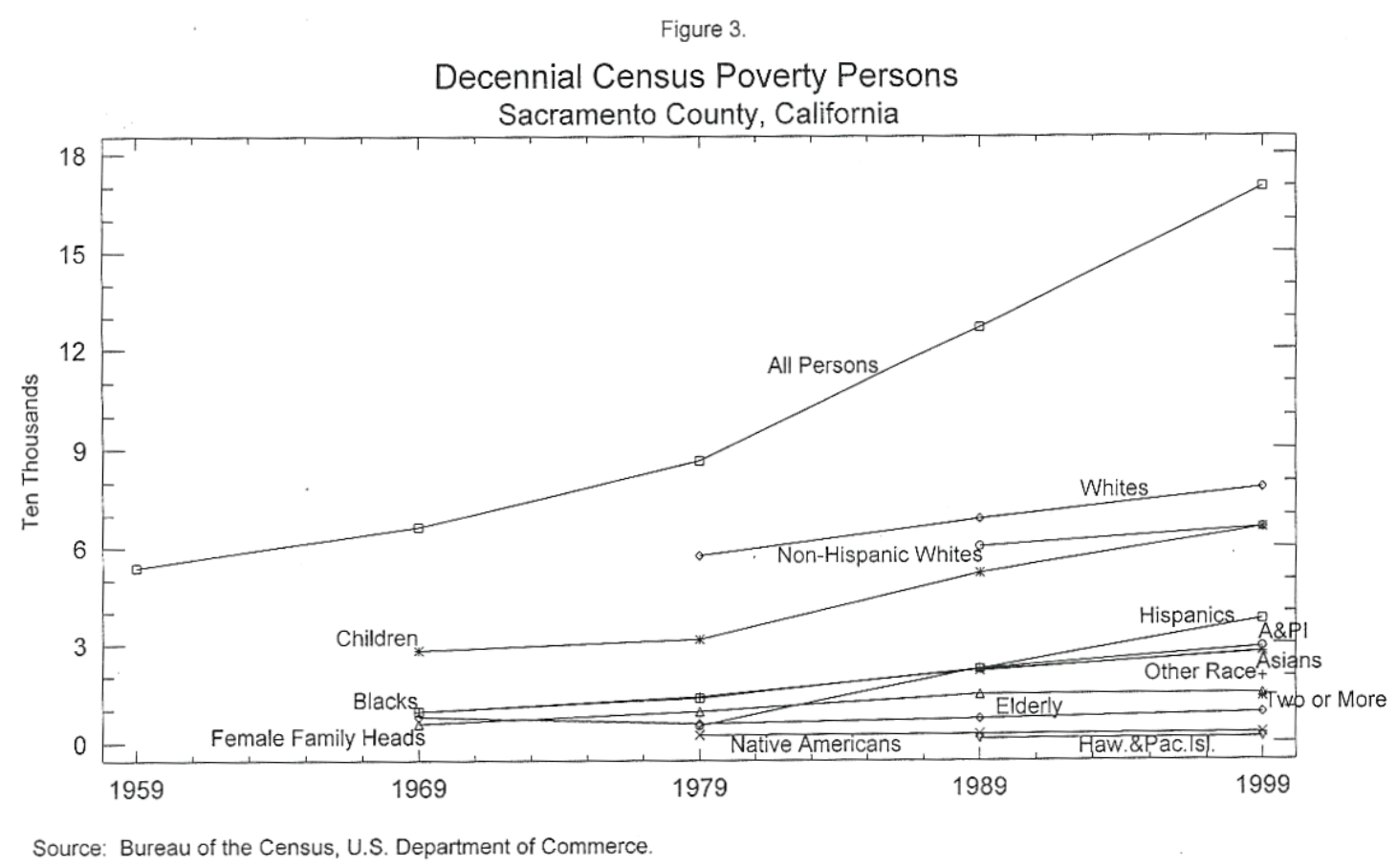

The evidence shows that:

- $\quad$ Among All Persons, over four decades the number who fell below poverty thresholds surged 215\% or by an annual average of over 5\%. In 1959, there were 54 thousand impoverished residents and, by 1999, that number had jumped to almost 170 thousand. The decade of greatest increase was the 1980 s at $47 \%$. During the most recent decade, the rate of growth was $34 \%$.

- $\quad$ Poverty among Asians \& Pacific Islanders exploded by 345\% during the 1980s and rose another 29\% in the 1990s. Over two decades, the rate of increase was a phenomenal 474\%, from 5 thousand to almost 29 thousand. As a consequence, this demographic category accounted for about $6 \%$ of overall County poverty in 1979 but $17 \%$ in 1999 . The $28 \%$ growth rate for Asians alone during the 1990 s exceeded the $24 \%$ rate for Native Hawaiians \& Other Pacific Islanders alone. (In 1999, Asians accounted for 95.2\% of the total poor of the combined A\&PI category.)

- $\quad$ Black poverty numbers swelled 189\% over three decades, from 9.4 thousand in 1969 to over 27 thousand in 1999 , or by an annual average rate of increase over 6\%. The 1980s was the period of greatest growth at $60 \%$. The group has increased its share of overall County poverty from $14 \%$ in 1969 to $16 \%$ in 1999.

- $\quad$ Poverty numbers among Children rose $134 \%$ over three decades, from 28 thousand to 66 thousand. The 1980 s was the period of greatest increase at $65 \%$. Their share of total poverty has declined from $42 \%$ in 1969 to $39 \%$ in 1999.

- $\quad$ The Elderly poor increased $11 \%$ between 1969 and 1999, from 7.8 thousand to 8.6 thousand. Their numbers fell $27 \%$ in the 1970 s, but rose by $26 \%$ and $21 \%$ in the 1980 s and 1990 s. As a share of overall County poor, they shrank from $12 \%$ to $5 \%$. 
- $\quad$ Poverty among Female Family Heads jumped 158\% between 1969 and 1999, from 5.7 thousand to 14.6 thousand. Their rates of increase plummeted, however, from $65 \%$ to just $1 \%$. As a portion of all County poor, their share peaked in 1989 at $11.4 \%$ before receding to $8.6 \%$ in 1999 .

- Hispanic poverty numbers exploded by $299 \%$ between 1969 and 1999, from 9.4 thousand to 37.4 thousand, or by a $10 \%$ annual average rate of change. Their rates of increase over three decades accelerated from $41 \%$ to $68 \%$. As a consequence, their share of total County poor expanded in continuous steps from $14 \%$ to $22 \%$.

- $\quad$ Native American poor persons have grown 19\%, from 2.3 thousand in 1979 to 2.7 thousand in 1999. Although their share of overall County poverty fell from $2.7 \%$ to $1.6 \%$, their rate of increase in poverty numbers doubled from $6 \%$ to $12 \%$.

- $\quad$ In 1999, the Some Other Race poor numbered 19.5 thousand and accounted for $11.5 \%$ of all County poor.

- In 1999, Two or More Races had 13.4 thousand persons below the poverty level and represented almost 8\% of the total poor.

- White poor grew 36\% over two decades, from 57.4 thousand in 1979 to 78 thousand in 1999. Their rates of increase declined from $20 \%$ to $13 \%$ and, as a share of overall County poverty, Whites shrank from $66 \%$ to 46\%. Non-Hispanic White poverty persons grew 10\% between 1989 and 1999, from 60.2 thousand to 66 thousand, but their share of total County poor declined from $48 \%$ to $39 \%$.

\subsection{The Present}

Before looking to the future, let us examine the most current decennial census cross-sectional picture of Sacramento County. Figure 4 illustrates comparative poverty rates among the various demographic groups in 1999 (from Census 2000). In descending order, those segments with the highest incidences of poverty are: Blacks (at 23.7\%), Female Family Heads (23.4\%), Native Hawaiians \& Other Pacific Islanders alone (22.2\%), Some Other Race (22.0\%), Native Americans (20.9\%), Asians \& Pacific Islanders (20.6\%), Asians alone (20.5\%), Children (20.2\%), Hispanics (19.5\%), Two or More Races (17.7\%), Whites in general (10.1\%), Non-Hispanic Whites (9.5\%) and the Elderly $(6.6 \%)$. The overall poverty rate for the County is $14.1 \%$.

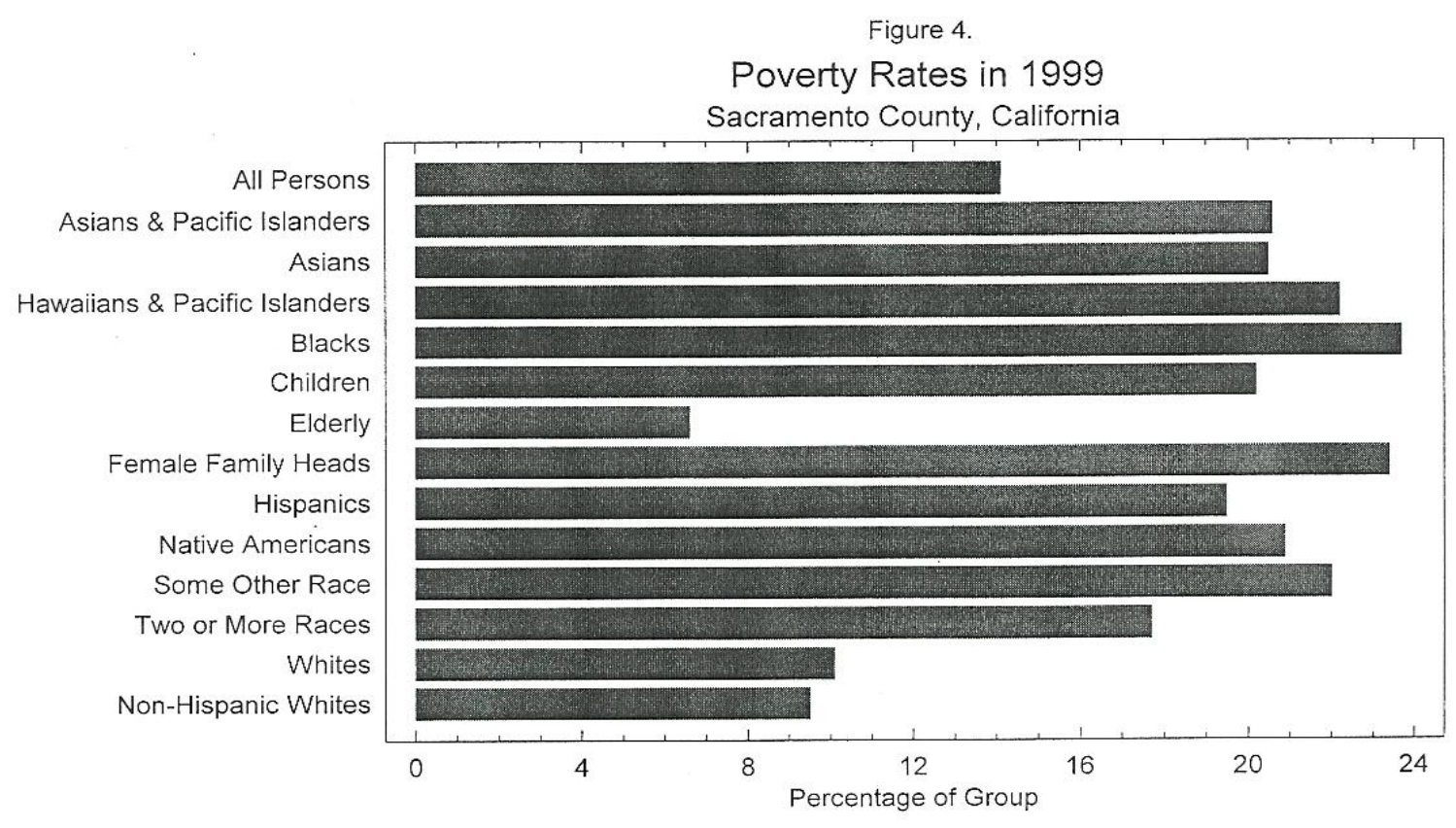

Source: Bureau of the Census, U.S. Department of Commerce. 
Table 4 and Figure 5 report and illustrate each demographic group's latest decennial shares of poverty and population. For example; although Female Family Heads represent 5.2\% of the total County population, they account for $8.6 \%$ of all poverty persons. Table 4 further presents the ratio of each group's percentage share of total poverty to percentage share of total population. The purpose of the right-hand column is to determine whether a group accounts for its "fair" share of area poverty. A value of one indicates an "appropriate" poverty share, a ratio greater than one indicates an "excessive" share and a ratio of less than one indicates a disproportionately small share.

Table 4: Poverty \& Population Shares Sacramento County, California

\begin{tabular}{|c|c|c|c|c|c|}
\hline \multirow[t]{2}{*}{ Group } & \multicolumn{2}{|c|}{1999 Poverty } & \multicolumn{2}{|c|}{2000 Population } & \multirow{2}{*}{$\begin{array}{c}\text { Poverty \%/ } \\
\text { Population \% }\end{array}$} \\
\hline & Persons & Percent of Total & Persons & Percent of Total & \\
\hline All Persons & 169,784 & 100.0 & $1,223,499$ & 100.0 & 1.00 \\
\hline Asians \& Pacific Islanders & 28,878 & 17.0 & 142,163 & 11.6 & 1.46 \\
\hline Asians & 27,499 & 16.2 & 134,899 & 11.0 & 1.47 \\
\hline Hawaiians \& Pacific Islanders & 1,379 & .8 & 7,264 & .6 & 1.37 \\
\hline Blacks & 27,184 & 16.0 & 121,804 & 10.0 & 1.61 \\
\hline Children & 65,901 & 38.8 & 326,698 & 26.7 & 1.45 \\
\hline Elderly & 8,628 & 5.1 & 135,875 & 11.1 & .46 \\
\hline Female Family Heads & 14,580 & 8.6 & 63,910 & 5.2 & 1.64 \\
\hline Hispanics & 37,441 & 22.1 & 195,890 & 16.0 & 1.38 \\
\hline Native Americans & 2,749 & 1.6 & 13,359 & 1.1 & 1.48 \\
\hline Some Other Race & 19,540 & 11.5 & 91,541 & 7.5 & 1.54 \\
\hline Two or More Races & 13,384 & 7.9 & 71,392 & 5.8 & 1.35 \\
\hline Whites & 78,049 & 46.0 & 783,240 & 64.0 & .72 \\
\hline Non-Hispanic Whites & 66,024 & 38.9 & 706,655 & 57.8 & .67 \\
\hline
\end{tabular}

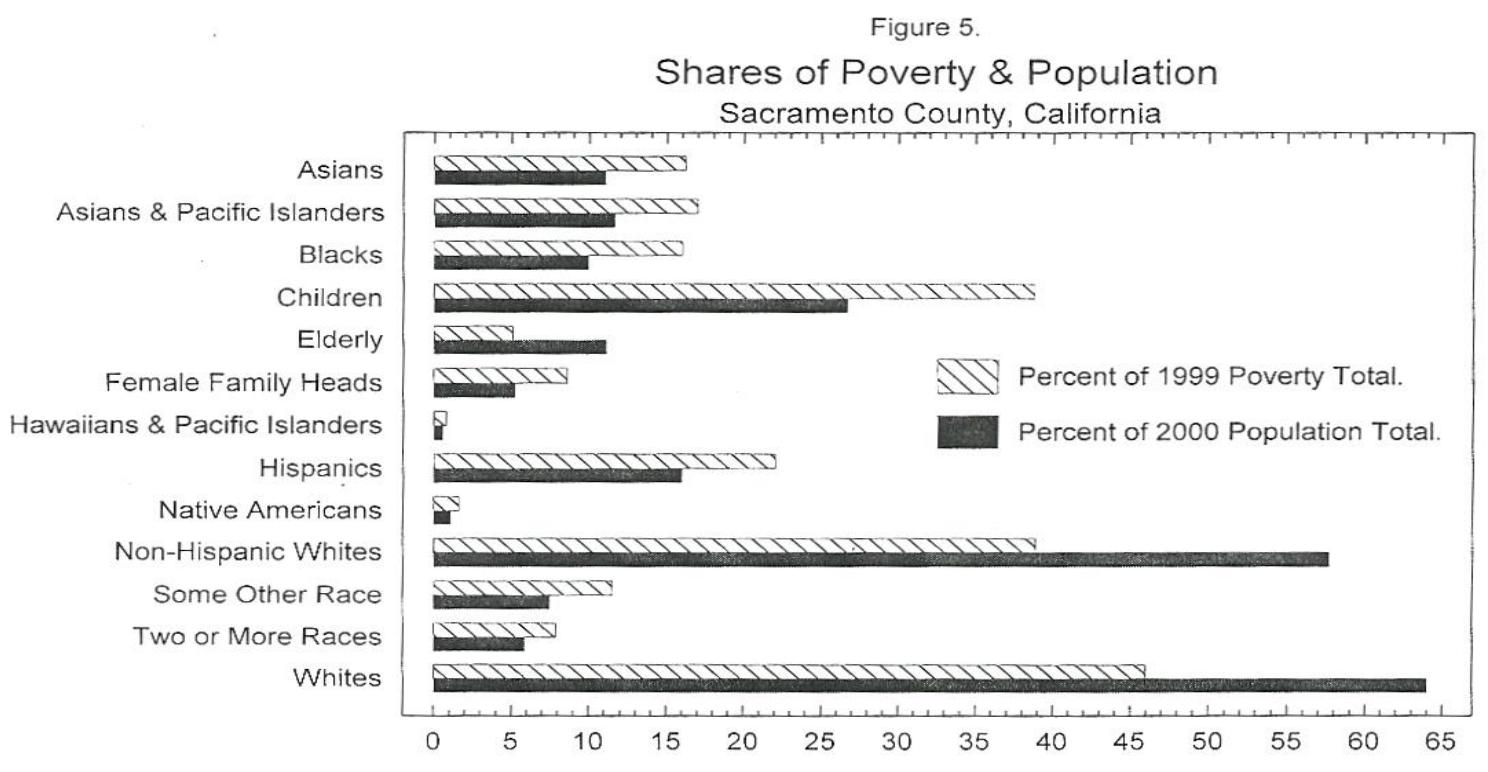

Source: Bureau of the Census, U.S. Department of Commerce. 
In descending order, those demographic groups which account for inordinately large shares of County poverty are: Female Family Heads (with a ratio of 1.64), Blacks (1.61), Some Other Race (1.54), Native Americans (1.48), Asians alone (1.47), Asians \& Pacific Islanders combined (1.46), Children (1.45), Hispanics (1.38), Native Hawaiians \& Other Pacific Islanders alone (1.37) and Two or More Races (1.35). Those demographic groups accounting for disproportionately small shares are: Whites (.72), Non-Hispanic Whites (.67) and the Elderly (.46).

\subsection{The Future}

The future is presumed to be a reflection of the past. Projected trends in both rates and persons assume a continuation of patterns that have been previously established. These historical patterns are derived from the most recent three decennial census poverty years only $(1979,1989$ and 1999). Polynomial curvilinear regression models are employed to reveal the underlying trends, where "Year" is the controlling variable. In each case, the model is designed to account for $100 \%$ of the pattern of the three data points. Table 5 presents the resulting computed regression coefficients.

Table 5: Regression Estimates Sacramento County, California

\begin{tabular}{|l|c|c|c|}
\hline \multicolumn{2}{|c|}{ Poverty Rates } & \multicolumn{2}{c|}{ Coefficient } \\
\hline Group & Constant & \multicolumn{2}{c|}{ Second Degree } \\
\hline All Persons & & -5.822 & 0.0015 \\
Asians \& Pacific Islanders & $5,658.28$ & 274.892 & -0.069 \\
Blacks & $-273,764.0$ & -0.0015 \\
Children & $-5,880.35$ & 5.952 & -0.017 \\
Elderly & $-67,711.9$ & 67.866 & 0.005 \\
Female Family Heads & $19,926.6$ & -19.96 & -0.0255 \\
Hispanics & $-100,385.0$ & 101.204 & -0.006 \\
Native Americans & $-23,836.6$ & 23.928 & 0.0255 \\
Whites & $101,169.0$ & -101.574 & 0.0065 \\
\hline & $25,634.3$ & -25.812 & 13.44 \\
\hline All Persons & Poverty Persons & & -54.325 \\
Asians \& Pacific Islanders & $4.50115 \mathrm{E} 7$ & $-49,298.6$ & -14.425 \\
Blacks & $-2.17265 \mathrm{E} 8$ & $217,297.0$ & -33.055 \\
Children & $-5.83862 \mathrm{E} 7$ & $58,056.9$ & 0.11 \\
Elderly & $-1.34146 \mathrm{E} 8$ & $133,216.0$ & -24.655 \\
Female Family Heads & $146,539.0$ & -288.88 & 30.975 \\
Hispanics & $-9.8047 \mathrm{E} 7$ & $98,340.6$ & 0.79 \\
Native Americans & $1.20157 \mathrm{E} 8$ & $-122,009.0$ & -10.63 \\
Whites & $3.08343 \mathrm{E} 6$ & $-3,120.32$ & $43,316.3$ \\
\end{tabular}

To demonstrate how a specific regression equation yields annual estimates and projections, we can look at an example for All Persons. Projections of the rate and the number of total impoverished area residents in year 2009 are:

- $\quad$ Poverty Rate $=5,658.28-5.822(2009)+0.0015(2009)^{2}=16.0 \%$

- $\quad$ Poverty Number $=45,011,500-49,298.6(2009)+13.44(2009)^{2}=215,541$

Results of computations that are derived from the respective models are plotted in Figures 6 and 7. Smoothed trends with annual estimates are created for the time span 1979 to 2009. 
Figure 6 .

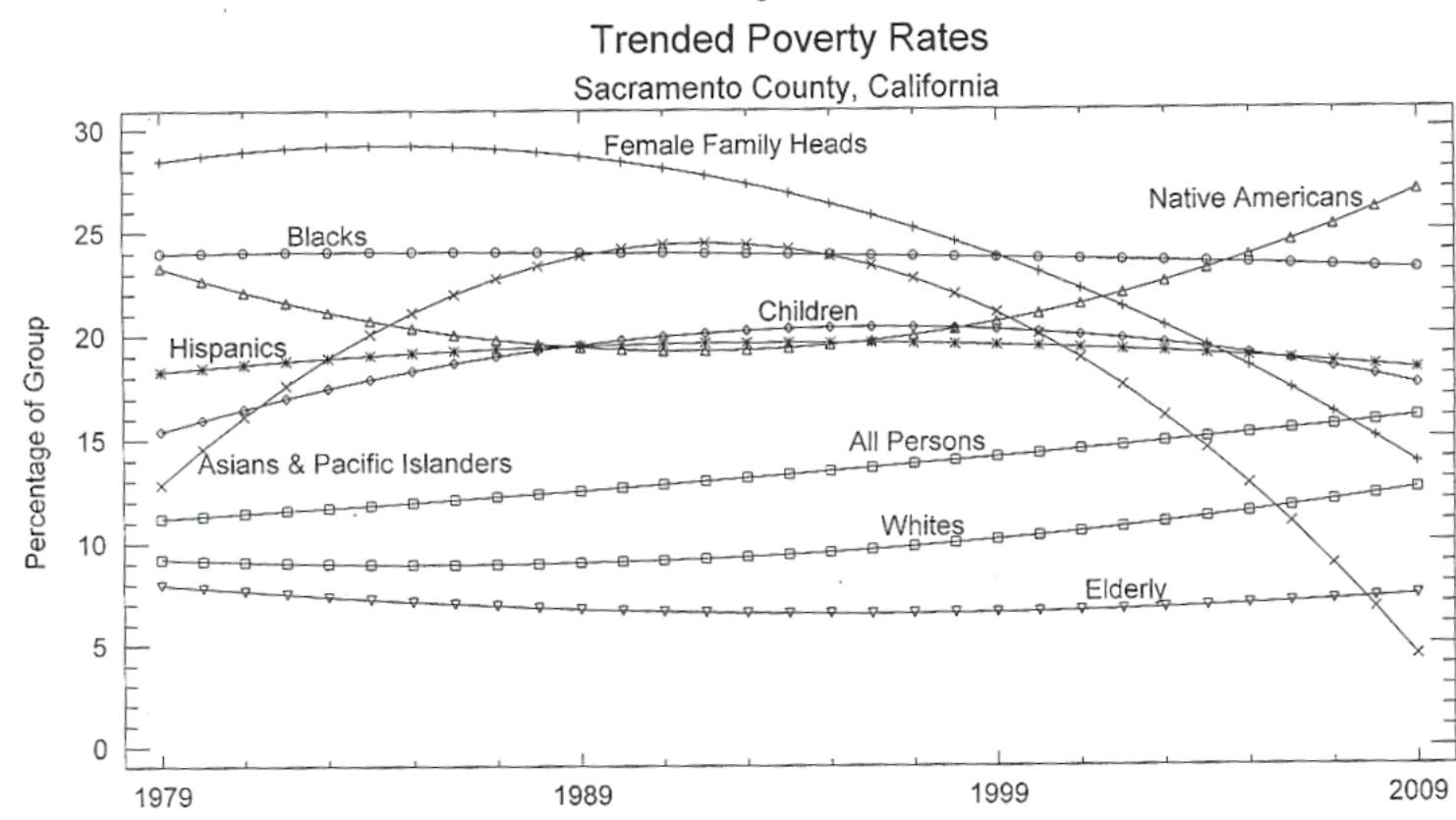

As seen in Figure 6, the independent demographic projections of rates of poverty for the individual groups indicate some significant changes. Between 1999 and 2009: the overall rate of poverty for Sacramento County is projected to increase $13.5 \%$, from $14.1 \%$ in 1999 to $16.0 \%$ in 2009 ; the rate for Asians \& Pacific Islanders is seen to plummet $79 \%$, from $20.6 \%$ to just $4.4 \%$; Black rates will recede $3 \%$, from $23.7 \%$ to $23.1 \%$; rates for Children will drop $13 \%$, from $20.2 \%$ to $17.5 \%$; the Elderly will see a $12 \%$ increase, from $6.6 \%$ to $7.4 \%$; Female Family Heads will experience a $41 \%$ drop-off, from $23.4 \%$ to $13.8 \%$; Hispanic poverty rates will decline $6 \%$, from $19.5 \%$ to $18.3 \%$; rates for Native Americans will surge $29 \%$, from $20.9 \%$ to $26.9 \%$; White poverty rates will jump $24 \%$, from $10.1 \%$ to $12.5 \%$.

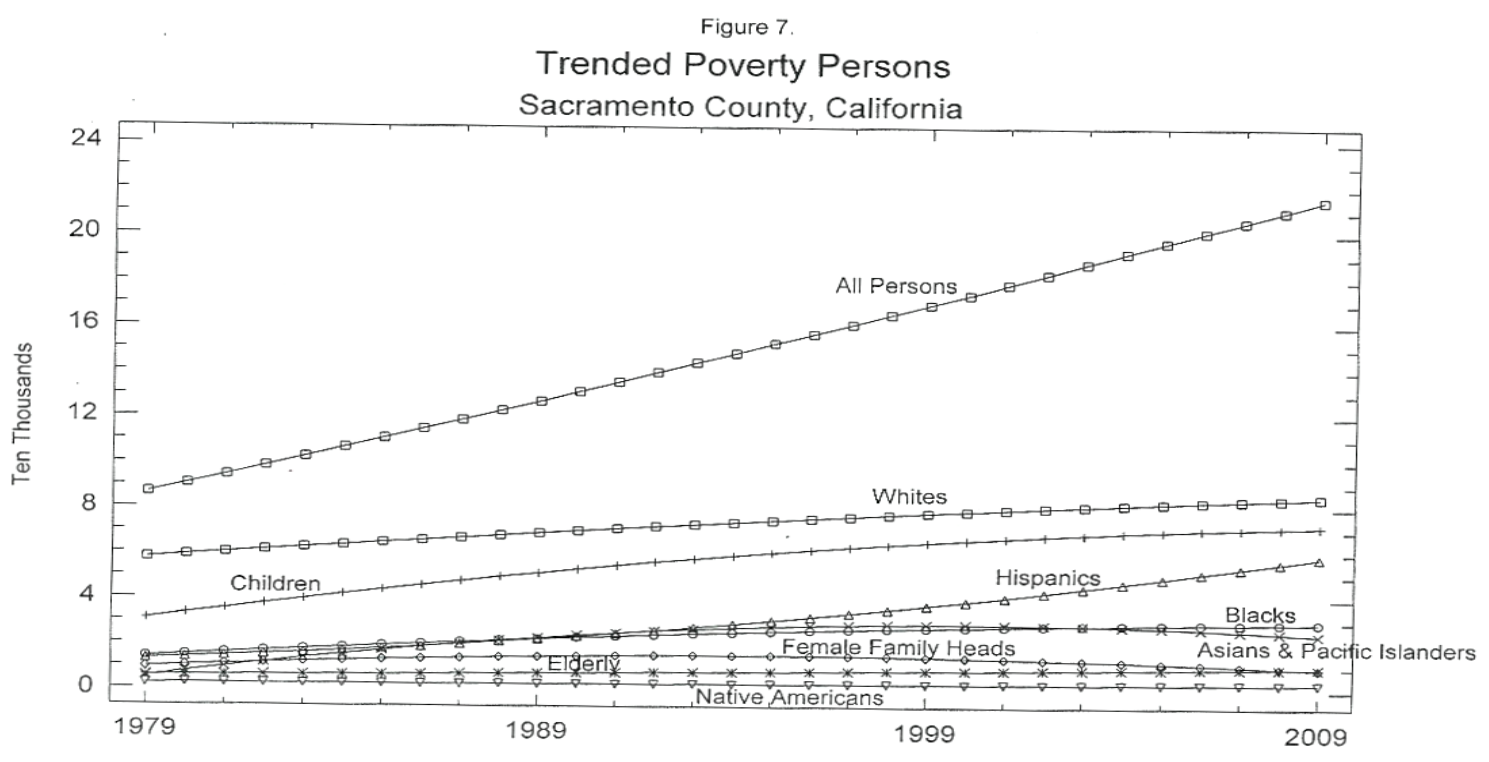


Figure 7 indicates the independent demographic projections of the number of persons in poverty. By year 2009, the total number of impoverished County residents is predicted to swell by 27\%, from 170 thousand to 216 thousand; Asian \& Pacific Islander poverty persons will decline 15\%, from 29 thousand to 25 thousand, and their share of total County poverty will drop from $17 \%$ to $11 \%$; Black poverty will grow $9 \%$, from 27 thousand to 30 thousand, and their share of overall poverty will recede from $16 \%$ to $14 \%$; poverty numbers for Children are seen to rise $10 \%$, from 66 thousand to 72 thousand, and their share of the total will fall from $39 \%$ to $34 \%$; Elderly poverty will grow $18 \%$, from 8.6 thousand to 10.1 thousand, but their share of overall County poor will contract from $5.1 \%$ to $4.7 \%$; Female Family Heads poverty persons will decrease 34\%, from 14.6 thousand to 9.7 thousand, and their share of total poverty will almost halve from $8.6 \%$ to $4.5 \%$; Hispanics are expected to see a $56 \%$ leap in poor persons, from 37 thousand to 59 thousand, and they will account for $27 \%$ of overall poverty compared to $22 \%$ in 1999; poor Native Americans will grow 17\%, from 2.7 thousand to 3.2 thousand, and their share of total poverty will diminish from $1.6 \%$ to $1.5 \%$; White poverty persons are expected to rise $9 \%$, from 78 thousand to 85 thousand. As a proportion of the total County poor, they are seen to decline from $46 \%$ to $40 \%$.

\section{Summary And Conclusions}

An important goal of this study has been to demonstrate a method of estimating and projecting annual demographic poverty at the sub-national level, where the County of Sacramento was chosen as the demonstration locale. Using benchmarks obtained from decennial censuses, poverty for various groups was traced. After examining the past for each group, independent demographic projections were extrapolated a decade to year 2009. The evidence is revealing and hopefully of help to County legislators and administrators and to public and private social service organizations. This methodology can be easily replicated at other sub-national jurisdictions and levels.

The overall picture indicates that the incidence of poverty will rise over the decade, in descending order of percentage change, for: Native Americans, Whites and the Elderly. The incidence will decline for: Asians \& Pacific Islanders, Female Family Heads, Children, Hispanics and Blacks. Across all demographic groups, the rate of poverty within the County is predicted to increase over the decade by $13.5 \%$ to $16.0 \%$.

Also, a steep increase is forecast by year 2009 for the number of impoverished residents within the County. In descending order, the demographic groups that are projected to grow most rapidly are: Hispanics, the Elderly, Native Americans, Children, Blacks and Whites. Those groups that are expected to decline are Female Family Heads and Asians \& Pacific Islanders. Within the decade, the total number of County persons beneath poverty thresholds is forecast to grow $27 \%$ and reach almost 216 thousand.

By 2009, in descending order, the greatest shares of area poverty will be identified with: Whites, Children, Hispanics, Blacks, Asians \& Pacific Islanders, the Elderly, Female Family Heads and Native Americans.

\section{Suggestions For Future Research}

One goal of this paper was to demonstrate a technique to estimate and project annual poverty at the subnational level. The locale of demonstration was the County of Sacramento in California. Future research, therefore, could apply the technique to other jurisdictions and to other sub-national levels -- such as states and metropolitan areas. In this study, the latest decennial census provided up-to-date data. However, as decennial censuses are conducted in the future, the data will provide additional and newly current benchmarks. Finally, this paper has projected poverty for Sacramento County for the forthcoming decade. When results appear from the next decennial census, the County projections presented here can be compared to the evidence for year 2009 and would serve to validate (or not) the methodology demonstrated in this paper. Thus, this study offers a full agenda of opportunities for further research.

\section{Acknowledgements}

This study was supported by a summer research fellowship from the CSUS Research and Creative Activity Award Program. 


\section{References}

1. Bureau of the Census, U.S. Department of Commerce, Washington, DC, http://www.census.gov/hhes/www/poverty.html.

2. Bureau of the Census, U.S. Department of Commerce, Statistical Abstract of the United States: 2000 (120 th edition), Washington, DC, Table 771, p. 490, 2000.

3. Mogull, Robert G., "Modeling Annual Poverty in a Metropolitan Area," Journal of Applied Business Research, Vol. 18, No. 1, pp. 51-60, 2002.

4. Mogull, Robert G., “Annual Estimates of California's Poor: 1959 Through 1990,” American Journal of Economics and Sociology, Vol. 50, No. 3, pp. 299-312, 1991.

5. $\quad$ Orshansky, Mollie, "How Poverty is Measured," Monthly Labor Review, Vol. 92, No. 2, pp. 37-41, 1969.

6. Orshansky, Mollie, "Who's Who Among the Poor: A Demographic View of Poverty," Social Security Bulletin, Vol. 28, No. 7, pp. 3-32, 1965.

7. Orshansky, Mollie, "Counting the Poor: Another Look at the Poverty Profile," Social Security Bulletin, Vol. 28, No. 1, pp. 3-29, 1965.

Notes 